\title{
Os paradigmas dominantes na gestão da educação superior a partir da autoavaliação: uma revisão integrativa
}

\author{
Marina Keiko Nakayama ${ }^{1}$ \\ Jactania Marques Muller ${ }^{2}$ \\ Emílio da Silva Neto ${ }^{3}$
}

\begin{abstract}
RESUMO
A educação superior vem passando por uma transformação substancial em seu modelo gerencial, tanto em nível mundial como no Brasil. Isso é causado, principalmente, pelas diversas lógicas dominantes que se encontram em cada contexto, orientando uma reflexão sistemática sobre sua estrutura gerencial e que se constitui a partir da autoavaliação. Sob esse pressuposto, o artigo busca contextualizar uma reflexão sobre essas mudanças, buscando um entendimento sobre os paradigmas que orientam a perspectiva gerencial na educação superior e sobre as tendências que se apresentam para o segmento em nível mundial e no Brasil. Por meio de uma revisão integrativa que utilizou as bases SCOPUS, EBSCO e SCIELO, considerando também materiais experimentais e empíricos, os 46 artigos utilizados permitem concluir que há uma tendência paradigmática dicotômica quando se consideram os contextos estudados. Enquanto em nível internacional a lógica predominante é a interpretativista, no Brasil, em função da forte influência da lógica mercantil na educação superior, há uma tendência funcionalista, somativa e regulatória, fortalecendo o controle do estado no contexto da educação superior.
\end{abstract}

Palavras-chave: Paradigmas, Autoavaliação, Educação Superior.

\section{The dominant paradigms in management of higher education from self-assessment: a integrative review}

\section{RESUMO}

Higher education has undergone a substantial transformation in its management model, both globally and in Brazil. This is caused mainly by the different dominant logics that are in each context, guiding a systematic reflection on its management structure and that it is from the self-assessment. Under this assumption, the article seeks to contextualize a reflection on these changes, seeking an understanding of the paradigms that guide managerial perspective in higher education and on the trends that are presented for the segment worldwide and in Brazil. Through an integrative review using the SCOPUS, EBSCO and SCIELO bases, also considering experimental and empirical materials, 46 articles used indicate that there is a dichotomous paradigmatic trend when considering the contexts studied. While internationally the prevailing logic is interpretive in Brazil, due to the strong influence of market logic in higher education, there is a functionalist, summative and regulatory trend, strengthening state control in the context of higher education.

Keywords: Paradigms, Self-assesment, Higher Education

\footnotetext{
1 Doutorado em administração na UFRGS, com estágio na HEC-Montreal-Canadá (1997). Mestrado em Administração e Bacharelado em psicologia. Docente em Desenvolvimento Humano e Métodos qualitativos no PPG em Engenharia e Gestão do Conhecimento da UFSC e de Engenharia e Gestão da Inovação no curso de Engenharia de Materiais. E-mail marina@egc.ufsc.br

${ }^{2}$ Mestranda em Gestão do Conhecimento pela UFSC. Especialista em Gestão de Pessoas pelo Instituto de PósGraduação (Esucri) e graduada em Psicologia pela UFSC. E-mail jac-muller@ hotmail.com

${ }^{3}$ Doutorando do Programa de Pós-Graduação em Engenharia e Gestão do Conhecimento da UFSC. Aluno da Wiesbaden Business School, Alemanha. E-mail emiliosneto@ netuno.com.br
} 


\section{INTRODUÇÃO}

A educação superior busca a convergência com os paradigmas do conhecimento científico para constituir uma nova dinâmica gerencial, preponderante em função da complexidade do segmento. Isso pressupõe o entendimento das visões de mundo que são compartilhadas nesse cenário, orientando a construção de um escopo sistemático de conceitos que deve orientar a dinâmica desse tipo de entidade. No contexto atual, especialmente em função dos diversos impactos da globalização, do conhecimento e dos ensejos de uma nova sociedade, é imprescindível que se criam novas visões que vão permitir um olhar para além dos velhos paradigmas gerenciais desse modelo de organização, permitindo a construção de modelos de gestão inovadores e adaptados ao contexto dinâmico do setor.

É possível perceber que a educação superior, independente do modelo institucional, vem passando por uma mudança disruptiva que causa incertezas no segmento. As principais questões que se colocam estão relacionadas com o entendimento da lógica capitalista e neoliberal, as quais estão se permeando pelos modelos educacionais ao redor do mundo.

Ao analisar o segmento pela lógica organizacional, e buscando amparo nas bases filosóficas do conhecimento científico, que na ótica de Morgan (1980) apresenta uma relação intrínseca com a gestão organizacional, é possível perceber que o modelo de gestão aplicado a esse tipo de organização vem passando por alterações abruptas em sua essência. Por isso, surge a possibilidade de buscar novas propostas a partir da criação de metáforas que envolvem a reflexão social a partir de movimentos multiparadigmáticos, permitindo o estudo de uma lacuna que abrange a discussão sobre a gestão da educação superior em âmbito mundial.

A autoavaliação, que nesse estudo é percebida como base desses movimentos multiparadigmáticos, é destacada por Mo et al (2006) como um instrumento que permite a construção de uma visão de mundo multiparadigmática. Além de fortalecer o construto gerencial da instituição, o processo permite que a reconstrução da epistemologia institucional, fortalecendo uma relação com o contexto e permitindo uma transposição de práticas e estruturas que moldam a essência desse modelo de organização.

O trabalho de Etzkowitz (2013) incita essa reflexão em nível mundial, já que destaca que o DNA da educação superior vem passando por uma mudança altamente transformadora, já que a instituição de educação superior assume a corresponsabilidade pelo desenvolvimento do entorno onde se localiza e por isso deve se posicionar para colaborar, sistematicamente, 
com a comunidade. O que o autor denomina de universidade empreendedora, se configura em uma entidade preocupada com a exploração de um potencial econômico e sustentável que fortalece a evolução social, desenvolvendo ativos que vão fomentar uma sociedade inteligente. Isso faz com que a universidade, ou qualquer modelo de educação superior, passe a se preocupar com a criação de uma nova identidade, constituindo mecanismos que permitam a construção de uma nova visão de mundo por parte da instituição e que é validada pelo processo participativo de discussão sobre sua estrutura.

No Brasil, mais especificamente a partir de 2004 com o surgimento do Sistema Nacional de Avaliação da Educação Superior (SINAES), essa discussão ganha notoriedade em função da proposição que o sistema faz de equilibrar os paradigmas existentes em um segmento que era marcado pela expansão orientada pela lógica mercantil. A proposta buscou criar uma visão sistêmica da educação superior a partir de instrumentos somativos e formativos, criando uma visão equilibrada entre as proposições emancipatórias e somativas.

Os trabalhos de Polidori, Fonseca e Larrosa (2007), de Sguissardi (2008) e de Silva e Alfredo (2011) auxiliam essa compreensão e destacam que a avaliação da educação superior, principalmente a partir do processo de autoavaliação, proporcionou a oportunidade de uma nova construção paradigmática por parte das instituições de educação superior no Brasil. Ao orientar esse novo construto, o processo fez com que a educação superior no Brasil buscasse se desenvolver sob óticas hegemônicas e alinhadas a partir de uma analogia com o que foi definido por Morgan (1980), especialmente no lume funcionalista e interpretativista.

Na busca desse entendimento, o artigo busca construir uma revisão integrativa que tem o objetivo de analisar, sob a ótica dos paradigmas propostos por Morgan (1980), qual é a visão de mundo predominante no processo de autoavaliação das instituições de educação superior. Por meio dessa estrutura, a pesquisa se constitui em quatro seções. Na primeira, a introdutória, surge uma visão geral do tema e o destaque de lacunas que norteiam o trabalho desenvolvido. Na segunda, encontra-se a delimitação metodológica utilizada e o destaque para os resultados da coleta de dados realizada. Já a terceira, busca sintetizar os conceitos e promover uma discussão que auxilie na resposta às questões centrais do estudo, orientando a discussão sobre a mudança paradigmática ocasionada pela influência da autoavaliação. $\mathrm{Na}$ quinta seção surge uma reflexão sobre os paradigmas dominantes e, por fim, na sexta seção, surgem as considerações finais e os apontamentos que fortalecem as premissas discutidas na pesquisa. 


\section{DELIMITAÇÕES METODOLÓGICAS}

De acordo com os estudos de Mendes, Silveira e Galvão (2008), a revisão integrativa é uma proposta de estudo das práticas baseadas em evidências que pode colaborar com a tomada de decisão em diversos ambientes organizacionais. Isso permite que um assunto específico possa ser tratado a partir de suas lacunas, considerando a síntese de estudos empíricos, experimentais e não experimentais publicados em bases dados de reconhecida relevância. Além de se constituir em um método valioso para o ordenamento do conhecimento inédito no contexto de estudo, a revisão integrativa ainda permite que o conhecimento científico existente e disponível possa ser agrupado para criar uma visão geral sobre um determinado assunto.

As assertivas de Souza, Silva e Carvalho (2010), destacam que a visão geral promovida pela revisão integrativa também permite que se criem novos conhecimentos substanciais para o objeto ou área de estudo, já que a prática baseada em evidencias auxilia no entendimento rigoroso do problema elencado.

Sob essa consideração, o artigo se configura em uma revisão integrativa, a qual busca elucidar uma problemática que envolve as seguintes questões: a) Com base nos paradigmas propostos por Morgan (1980) e de acordo com empíricos já publicados, qual é a visão de mundo predominante no processo de autoavaliação de instituições de educação superior? b) De acordo com os estudos já publicados sobre a autoavaliação da educação superior em nível mundial, qual é a visão geral do processo sob a ótica paradigmática proposta por Morgan (1980)? c) Em qual paradigma está sustentado o modelo do SINAES? e d) Qual é a tendência paradigmática encontrada na educação superior internacional e brasileira, tendo como pano de fundo a autoavaliação?

Para responder a essas questões, o estudo buscou artigos publicados em periódicos científicos disponíveis em bases de dados notadamente reconhecidas como relevantes pela comunidade científica. As bases consultadas foram a Scopus, Scielo e a EBSCO, apresentam materiais publicados sobre a avaliação da educação superior, a autoavaliação, sobre conhecimento científico e sobre o Sistema Nacional de Avaliação da Educação Superior (SINAES) que foi implantado no Brasil a partir de 2004. A coleta de dados foi desenvolvida por meio de alguns critérios que seguem consideraram as seguintes etapas: 
1. Artigos que trazem a relação entre os termos "autoavaliação e educação superior", entre "educação superior e conhecimento científico" e entre "educação superior e paradigmas". Os termos em inglês também foram utilizados.

2. Artigos publicados a partir de 2004, já que é o ano em que o SINAES é instituído no Brasil e o momento no qual a expansão da educação superior brasileira considera a autoavaliação como mecanismo norteador.

3. Artigos que consideram os temas da pesquisa em nível mundial e em nível nacional, e que contenham os termos pesquisados no título ou nas palavras-chave.

4. Seleção de artigos que contenham o texto integral.

Após essa seleção, aplicou-se um novo filtro que excluiu artigos que tratasse especificamente de estruturação metodológica do conhecimento científico, os quais estariam alinhados a aspectos que limitariam ou reduziriam a discussão no âmbito gerencial a um aspecto meramente metodológico. Dessa forma, a primeira busca encontrou 94 artigos, dos quais 46 passaram a compor o estudo em função de apresentarem uma relação direta entre a autoavaliação e a gestão da educação superior, notadamente sob uma lógica gerencial.

\section{ANÁLISE DESCRITIVA DA REVISÃO: SÍNTESE DOS PRINCIPAIS TRABALHOS}

Os trabalhos publicados mostram que a educação superior passa por uma transição significativa em função da reconstrução de sua identidade, já que a sociedade busca por uma instituição que tenha objetivos convergentes e interdependentes com os que são discutidos em um determinado contexto social. Essa mudança pode ser compreendida sob a ótica das contribuições de Khun (2006), já que a educação superior, independentemente de seu posicionamento geográfico, rompe suas fronteiras paradigmáticas em busca da construção de uma nova visão de mundo que extrapole as construções limitadas já constituídas. Tal aspecto vai ao encontro do que propõe Etzkowitz (2013), já que o momento de reconstrução da educação superior passa pela instituição de sua relevância social, diretamente vinculada a sua capacidade empreendedora, fortalecendo um novo paradigma observado por essas instituições.

Nos 46 artigos selecionados, os quais foram publicados a partir de 2004, percebe-se uma crescente tendência dos pesquisadores para o estudo dessa mudança de paradigma. Esse interesse acadêmico fundamenta-se em uma revolução cultural pela qual os países ocidentais vêm passando desde o final da segunda guerra mundial. Essa mudança se ampara na 
autoavaliação como instrumento de apoio, já que é um mecanismo de entendimento da realidade dominante na instituição, já que envolve uma série de paradigmas que envolvem a construção de uma identidade institucional.

A partir de 2004, em nível internacional, os artigos que tratam dessa mudança de paradigma criticam o "Tratado de Bolonha" como documento norteador da proposta de alteração acadêmica e administrativa da educação superior em nível mundial. Tendo como pano de fundo o trabalho de Morgan (1980), é possível propor um cenário de transposição do paradigma funcionalista para o paradigma interpretativista no momento em que se analisa a gestão desse modelo de organização. Isso se dá, especialmente, em função da importância da participação dos agentes sociais na alteração sistemática da realidade dominante da universidade, a qual buscou se constituir ao longo de um processo participativo, reflexivo e sistemático.

O trabalho de Welsh (2010), que buscou realizar uma análise dessa alteração de paradigma no âmbito da educação superior da Alemanha, e no trabalho de Kurelic (2009), o qual criticou severamente a mudança de cenário no contexto da educação superior da Croácia, se alinham a esse entendimento e apresentam uma discussão sobre a importância dessa participação sistemática. Em ambos os modelos discutidos, tanto no alemão quanto no croata, pode-se identificar que, apesar das críticas ao que propôs o Tratado de Bolonha, a sociedade passa a ser interdependente da universidade no sentido de construção da missão dessa entidade. Essa participação social complexa vem se moldando ao longo dos anos, ensejando estudos e pesquisas que auxiliem a construção das bases desse processo.

As experiências internacionais que se apresentam nas publicações também destacam a mudança de paradigma que ocorre no contexto do ensino e aprendizagem, especialmente em função do avanço da pesquisa qualitativa como forma de produção de conhecimento na educação superior. O trabalho de Majora e Savin-Badenb (2010) propõe o estudo do contexto social a partir de um avanço significativo da visão de mundo interpretativista, fazendo com que o ensino e a aprendizagem tenham significado contextual, fortalecendo a analogia com as definições de Morgan (1980) e que é a base para este artigo.

O trabalho de Ong (2012) também segue essa reflexão, mas promove um viés para a alteração do paradigma da liderança na educação superior, destacando que a gestão deve compreender as alterações contextuais complexas que envolvem o segmento. Ao se posicionar dessa maneira, a universidade deve orientar, sistematicamente, a construção de um 
novo cenário voltado às construções sociais relevantes, devido a necessidade de um maior envolvimento dessa entidade no desenvolvimento social sustentável.

Etzkowitz et al.. (2008) podem confirmar essa percepção, já destacavam a importância dessa participação social na universidade, orientando a visão de mundo voltada para uma relação direta entre empresa, governo e universidade. Além de construir um novo cenário para a atividade da universidade, isso fortaleceria uma série de parcerias orientadas para o desenvolvimento sustentável, fundamentando uma alteração disruptiva de paradigma que permeia o ambiente da educação superior em âmbito mundial.

Já no contexto brasileiro, sobretudo a partir de 2004, percebe-se que a construção do modelo de avaliação que é vigente até os dias atuais, nesse caso o SINAES, também orientou uma mudança drástica de paradigma na educação superior, já que propôs um equilíbrio entre as visões dominantes. Em um primeiro momento, o modelo permitiu que o funcionalismo e o interpretativisvo pudessem se coadunar em prol do desenvolvimento da educação superior em nível nacional. Porém, o que se vê é que, até 2008, os trabalhos apresentam um cenário de disrupção e entendem que a mudança está ocorrendo, porém de maneira morosa e com uma tendência ao funcionalismo.

Esse cenário pode ser percebido no trabalho de Barreyro (2008), Bittencourt, Casartelli e Rodrigues (2009), Polidori (2009), Bittencourt et al.. (2010) e Weber (2010), já que as proposições funcionalistas e somativa voltam a se impor no contexto paradigmático da educação superior por meio de indicadores que regulam a atividade das instituições. Desse modo, a visão de mundo que passa a predominar, especialmente no contexto das instituições privadas, propõe que a finalidade principal da atividade educacional possa ser mensurada apenas por índices que se tornam descontextualizados se não estiverem alinhados a um plano de desenvolvimento institucional.

Com o surgimento do Conceito Preliminar de Curso e do Índice Geral de Cursos, indicadores preconizados pela Portaria Normativa No 40, de 13 de dezembro de 2007, e que reconstruíram o paradigma na educação superior atual, existem trabalhos que destacam as tentativas de se propor uma visão paradigmática interpretativista nesse contexto altamente complexo. Nesses materiais, o que se percebe é uma tentativa de promover uma nova discussão sobre a importância da visão interpretativa no contexto da avaliação, valorizando a visão de mundo e as características dominantes de cada modelo institucional, tento na autoavaliação um instrumento de fortalecimento desse pressuposto. Nas conclusões, porém, o 
que se encontra é umas práxis fortemente vinculada à regulação, impedindo o desenvolvimento de um modelo autônomo e emancipado.

Em contrapartida, é possível identificar nos trabalhos de Vieira e Freitas (2010), Francisco et.al. (2012) e Oliveira et al.. (2013) aspectos que promovem a discussão sobre uma nova alteração de paradigma na educação superior voltada para uma visão interpretativa. Os autores, de uma maneira geral, propõem uma visão de mundo diferente daquela praticada pelos órgãos reguladores, a qual está pautada no aspecto processual que se consolida com a autoavaliação, que é considerado um instrumento de significativa importância no processo de alteração paradigmática desse modelo de organização social.

\section{A MUDANÇA DE PARADIGMA NA EDUCAÇÃO SUPERIOR: UMA NOVA VISÃO DE MUNDO PRODUZIDA PELA AUTOAVALIAÇÃO}

A autoavaliação é um mecanismo amplamente utilizado para fortalecer a atividade de investigação sobre o caminho percorrido por uma instituição de educação superior, tendo como base a identidade definida em um projeto institucional. Diante dessa premissa, alguns trabalhos internacionais, sobretudo os europeus, discutem o procedimento como um mecanismo norteador das ações estratégicas que visam consolidar a gestão acadêmica e administrativa de uma instituição de educação superior a partir de uma visão de mundo específica da comunidade acadêmica.

Em nível mundial, percebe-se que há uma tendência paradigmática que envolve a gestão da educação superior e que pode ser analogamente relacionada com os paradigmas propostos por Morgan (1980) e que se referem à gestão organizacional. Entre as visões que se constituem, destacam-se a visão paradigmática funcionalista e a interpretativista, já que essas envolvem os momentos pregressos e atuais da universidade no mundo e no Brasil.

Os trabalhos de Patterson (2004) e de Nathan e Whatley (2006), em nível internacional, e dos brasileiros Polidori, Fonseca e Larrossa (2007), Augusto e Balzan (2007), Sguissardi (2008), Silva e Alfredo (2011) e de Barreyro e Rothen (2014), destacam que a educação superior buscou a transposição de modelos e de suas estruturas a partir de uma práxis investigativa desenvolvida por sua comunidade interna. Em nível internacional, essa mudança de paradigma traduz uma nova forma de pensar instituída pelo Protocolo de Bolonha, o qual deveria reajustar a estrutura da universidade mundial e introduzir uma nova cultura universitária. Nessa linha, Patterson (2004) e Nathan e Whatley (2006), entendem que uma nova visão de mundo, baseada na interpretação do contexto por meio da autoavaliação, 
valorizando a relevância social da universidade, confirmando o que é discutido por Etzkowitz (2013).

No Brasil, os autores resgatam experiências anteriores com o Programa de Avaliação Institucional das Universidades Brasileiras (PAIUB) e destacam que desde o início da década de 1990 a visão funcionalista tem se tornado secundária no processo avaliativo. Apesar da influência política que é discutida por Dias, Horiguela e Marchelli (2006), a autoavaliação tenta se consolidar no início da década de 2000, mas, sem sucesso, acaba reduzida a uma avaliação que se constituía como um aspecto regulador, a qual dependia apenas da colaboração do estudante e não valorizava a construção ideologia que ocorria na instituição. Porém, em 2004 com a proposta do Sistema Nacional de Avaliação da Educação Superior (SINAES), a autoavaliação se institui como mecanismo norteador das ações acadêmicas e administravas, fortalecendo a participação social na gestão institucional.

Desde o surgimento da universidade, até a sua consolidação nos países desenvolvidos e nos emergentes, a visão de mundo que se constitui é voltada ora ao funcionalismo ora ao interpretativismo, já que o dinamismo imposto pelo capitalismo e pela introdução do conceito da competitividade no cenário social das instituições ensejou uma mudança radical na estrutura dessas entidades. Os trabalhos analisados mostram que países europeus, asiáticos e o Brasil seguiram essa linha a partir da instrumentação de seus procedimentos de avaliação interna, os quais fortaleceram a gestão participativa e a construção de uma nova identidade para a educação superior.

A partir dos anos 1990, sobretudo nos países asiáticos e europeus, excluindo-se Portugal em função do que é apresentado no trabalho de Marques (2010), percebe-se que há uma significativa alteração no padrão de atividade das instituições de educação superior. Os trabalhos que se apresentam destacam essa mudança, fazendo menção do aspecto processual da autoavaliação como uma forma de consolidação de uma nova visão de mundo. Mo et al.. (2006), Kushimoto (2009), Walser (2009) e Tarí (2011), apresentam essa realidade e destacam que a autoavaliação foi responsável por incutir uma visão de mundo ampla e generalista, permitindo que cada modelo institucional tenha a capacidade de qualificar suas atividades a partir das premissas que se fazem verdade no âmbito da instituição. Ao fazer uma analogia com o trabalho de Morgan (1980), percebe-se que o paradigma interpretativista passa, desde então, a ser o dominante no contexto da educação superior, permitindo que a relevância social possa ser uma competência da instituição. 
Em ressalva, o trabalho de Marques (2010) destaca que Portugal, em um determinado momento optou por fortalecer a ótica vigente no contexto de seu modelo, mantendo a visão funcionalista e pragmática e definiu a autoavaliação como um mecanismo secundário à gestão institucional. Porém, mesmo mantendo o padrão de prestação de contas e uma avaliação somativa, o modelo português entende a autoavaliação como uma forma de entender a dinâmica institucional, o que pode ser considerado um aspecto relevante na constituição dos padrões que configuram a identidade da instituição.

No âmbito da transposição para a visão interpretativista, outro ponto que aparece com relevância é o fato de que a autoavaliação é um instrumento que permite o entendimento dos paradigmas que são defendidos pelos modelos institucionais que estão permeados ao longo da sociedade. De liberais a conservadores, o processo avaliativo desenvolvido pela comunidade interna da instituição ajuda no fortalecimento dos modelos mentais defendidos e auxilia o entendimento dos caminhos propostos para uma mudança, seja ela disruptiva ou de base conceitual.

O trabalho de Welsh (2010) segue essa linha e destaca que o processo auxiliou a definição do paradigma defendido pelas instituições de educação superior da Alemanha em um momento de transformação social. Nas entrelinhas do artigo, fica perceptível a mudança que ocorreu a partir do evento que modificou a estrutura social da Alemanha, substituindo uma visão pragmática e funcionalista por uma visão dinâmica e interpretativista, permitindo que cada modelo institucional pudesse assumir suas características que os tornassem competitivos. A partir daí, percebe-se que o conceito de competitividade começa a orientar as ações estratégicas dos modelos institucionais da Alemanha, instituindo conceitos e ideias que deveriam promover a diversificação de modelos, a qual ocorreria por meio do envolvimento da comunidade acadêmica, da autonomia e da prestação de contas.

A autora ainda buscou sintetizar a revolução que transformou o paradigma dominante da educação superior naquele país e instituiu a possibilidade de uma construção autônoma da visão de mundo que seria defendida pelo conjunto de instituições que se constituíram após a queda do muro. Em suas contribuições, ela também destaca que a unificação determinou uma reflexão profunda sobre o papel das universidades alemãs, desencadeando um estudo profundo sobre um processo de reforma que tinha a intenção de unificar o sistema de educação superior do país. A autoavaliação, nesse contexto, ganha notoriedade em função de sua relevância na construção da identidade defendida pela universidade, tornando o modelo mais fluido e variado, em função da constituição das universidades de ensino e pesquisa. 
Schejbal (2012) traz à tona a discussão sobre a relevância e o impacto da transformação social causada pela educação superior em função da formação e do desenvolvimento de competências. A autoavaliação novamente aparece como forma de verificação das estruturas de formação da instituição e como método para mensurar a eficiência dos instrumentos utilizados para a construção da identidade institucional. Sob uma ótica voltada para a interpretação do mundo no qual a instituição está inserida, logo seguindo a lógica interpretativista de Morgan (1980), o trabalho pressupõe que a autoavaliação também é um mecanismo que permite o entendimento do mercado que envolve a instituição educacional, permitindo que a instituição compreenda o contexto no qual está envolvida.

\subsection{O paradigma dominante no brasil e sua relação com a autoavaliação}

A educação superior brasileira é complexa e permeada de estudos que buscam compreender a dinâmica do modelo proposto para o país. Desde o seu surgimento, no final do século XIX, até os dias atuais, o que se percebe é que poucas disrupções foram propostas ao longo do estabelecimento desse modelo educacional, fato que fica latente no momento em que se promovem comparações com outros modelos, como no caso do modelo alemão destacado por Welsh (2010). Atualmente, a complexidade torna-se ainda mais exacerbada em função da estrutura legal e regulatória do segmento, ensejando uma discussão que vai além dos aspectos estruturais e que busca entender o significado de cada instituição em seu contexto.

A universidade brasileira, fundada formalmente apenas no ano de 1920 e discutida nos estudos de Morhy (2004) sempre buscou pela proposição de um modelo próprio, mas sem um notório sucesso. De acordo com as reflexões produzidas por Barreyro e Rothen (2014), em função da complexidade do país e do envolvimento político da universidade, a busca por esse modelo sempre dependeu da ideologia governamental, o que talvez tenha impedido a consolidação da educação superior brasileira como uma grande precursora dos esforços vinculados à ciência e a tecnologia.

Durante o governo militar, a educação superior a educação superior se constituiu sob uma ótica paradigmática alinhada aos conceitos da regulação, principalmente em função dos interesses governamentais que se propunham para o desenvolvimento da sociedade brasileira. Ao buscar uma analogia com os conceitos propostos por Morgan (1980), pode-se inferir que esse momento buscava impor uma visão de mundo funcionalista à educação superior brasileira. 
Com sua evolução, a partir de uma série de dinâmicas e integrações que foram propostas a partir de 1930, a educação superior brasileira, especialmente por meio de políticas públicas e pelo envolvimento direto com instituições internacionais, passou a buscar um novo modelo de instituição e novos paradigmas passaram a se constituir ao longo das estruturas que se formavam. Nesse momento, como é possível perceber nas considerações de Sobrinho (2010), surge, com bastante propriedade, a participação social no construto institucional, permitindo a construção de uma visão de mundo alinhada com as transformações sociais pelas quais a sociedade passava.

$\mathrm{O}$ autor confirma esse pressuposto, destacando que:

Nesta década e meia, a sociedade brasileira vem experimentando significativas e rápidas transformações, as quais impõem à Educação Superior um leque amplo e contraditório de demandas que dificilmente podem ser adequadamente atendidas. Por ser um fenômeno humano e social, a educação é atravessada por contradições e conflitos relacionados com as diversas concepções de mundo e interesses dos indivíduos e dos diferentes grupos sociais. Essas contradições tendem a se acirrar crescentemente, em razão da importância que o conhecimento adquiriu na sociedade da informação, como principal motor da economia global, e do auge do individualismo e da competitividade (SOBRINHO 2010, p. 2).

No contexto atual, o que se percebe é uma tentativa de modificar o padrão dominante em função da busca por comportamentos relacionados com o empreendedorismo, orientados pela lógica do capital e pela demanda social que busca a inovação aplicada e o desenvolvimento sustentável como base para qualquer atividade social. Os trabalhos de Marchelli (2006) e de Peixoto (2010), mostram esse panorama e encaminham uma reflexão voltada para o entendimento de que a visão de mundo que permeia a educação superior brasileira está mudando. Isso acontece, sobretudo, por meio do sistema de avaliação implantado em 2004 e que valoriza a autoavaliação como um processo dialético de construção social e que serve como base para a gestão de qualquer modelo de instituição de educação superior.

Ao analisar os materiais, em analogia com o que é apresentado pelo trabalho de Morgan (1980), percebe-se que desde 2004 há uma abrupta mudança nos padrões dominantes no contexto gerencial da educação superior brasileira. A partir da instituição do SINAES como base para o processo avaliativo, valorizando a autoavaliação, percebe-se que a visão de mundo interpretativista é a dominante desde então. Apesar de uma série de aspectos introduzidos no âmbito político do segmento, como é o caso dos indicadores de qualidade propostos pela Portaria Normativa N. 23, de 29 de dezembro de 2010 e que se voltavam apenas ao aspecto somativo e regulador, há um esforço significativo da comunidade 
acadêmica para a introdução de uma visão de mundo que valorize a participação social, consolidada na interpretativista.

A autoavaliação, nesse sentido, é o principal mecanismo defendido pelos trabalhos brasileiros como forma de fomentar essa visão participativa e individual de cada instituição, permitindo que a interpretação do contexto, no caso da visão de mundo dessa instituição, possa ser o principal diferencial competitivo para a gestão institucional.

Isso pode ser percebido no trabalho de Pinto (2008), Zandavalli (2009) e De Sordi (2011), já que a autoavaliação é o principal mecanismo de interlocução social disponível no âmbito da instituição. Em outros trabalhos, como no caso de Francisco et al.. (2012) e Ribeiro (2012), é possível identificar que a autoavaliação se coloca como mecanismo de alteração paradigmática no momento em que constrói uma estrutura que fomenta a participação e o envolvimento social em torno de um projeto institucional. Além de consolidar princípios avaliativos e sociais, também permite que os critérios, alinhados à gestão, possam ser instituídos de maneira clara, alinhada com a principal finalidade da instituição que é definida a partir da interpretação de sua relevância no contexto.

\section{TENDÊNCIAS PARADIGMÁTICAS DA AUTOAVALIAÇÃO}

Ao longo dos anos, sobretudo em função da voraz influência do capital no contexto social nos países desenvolvidos e emergentes, a avaliação vem ganhando contornos de instrumento substancial na formatação de políticas públicas em todas as áreas. Na educação superior, essa tendência se institui pelo viés econômico e mercantil que a educação passa a assumir a partir do final do século XX, tal como é descrito por Esteves (2007). Isso se dá, entre outros aspectos, devido ao fato de que a educação passa a compor um escopo instrumento do desenvolvimento da sociedade, oferecendo pesquisas, projetos e insumos que podem ser fundamentais para o desenvolvimento de qualquer sociedade.

A autoavaliação, nesses ambientes, passa a ser um instrumento no qual a construção da identidade institucional se baseia, sendo utilizada como base para o desenvolvimento de projetos e de mecanismos que fortalecem a participação social na dinâmica institucional. Ao invés de ser percebida como um mecanismo de controle ou de regulação, a autoavaliação passa a ser percebida como uma forma de orientação gerencial que perpassa o tecnicismo e envolve os que são responsáveis pela condução gerencial e social da instituição de educação superior, permitindo que a relevância destacada por Etzkowitz (2013) possa se estabelecer e 
fazer com que a universidade tenha condições de alterar a dinâmica social do local onde se institui.

Os trabalhos de Pacheco (2014), Morgado (2014) e Machado (2014) mostram que há uma tendência dicotômica em função da complexidade do processo e dos diversos entendimentos que ela pressupõe no âmbito da educação superior. Essa tendência se constitui no contexto europeu, mas também se espalha ao longo de todo o mundo, sobretudo nos países emergentes, tendo no Brasil uma das metáforas que mais se destaca, em função do sistema complexo que é o SINAES.

A dicotomia que se constitui, considerando o pano de fundo proposto a partir das metáforas destacadas no trabalho de Morgan (1980), está relacionada a uma visão funcionalista e processual, já que a avaliação passa a ser um instrumento de fortalecimento de políticas públicas e, principalmente, de prestação de contas. A outra tendência, a interpretativista e voltada para a reflexão, que surge como sendo a base para a construção de políticas institucionais, as quais vão permitir a estruturação e o desenvolvimento da identidade institucional, também apregoada no Brasil em função de seu modelo complexo. Porém, em função da alta complexidade do modelo brasileiro, há uma difusão de tendências que envolvem direcionamentos da política governamental, as intenções do segmento público e as características do segmento privado.

A seguir, há um destaque dessa dicotomia que se constrói por meio de uma reflexão pontual sobre as tendências que se apresentam em nível mundial e sobre as tendências múltiplas que emergem no contexto brasileiro.

\subsection{Tendências do contexto europeu}

Os trabalhos de Ong (2012) e Kurelic (2009) mostram que a educação superior vem passando por uma transição em seus modelos institucionais, principalmente em países que são afetados pelos direcionamentos do Tratado de Bolonha. Especialmente no contexto europeu, surgem diversas mudanças disruptivas que buscam estruturar um modelo da educação superior que se torne convergente com as expectativas sociais dos países europeus e permita que diversas novas competências, tais como a mobilidade acadêmica, possam se estruturar o longo do segmento da educação superior.

Os autores destacam que a tendência europeia sinaliza o que deve permear as tendências em nível mundial, já que há uma influência significativa das condições propostas pelo Tratado de Bolonha na educação superior dos países americanos e asiáticos, sobretudo 
pela influência que é destacada por Nair e Prakash (2009) em função dos princípios de gestão do conhecimento que são emergentes no contexto desses países.

A autoavaliação, especialmente com base no trabalho de Kurelic (2009), passa a ser um instrumento que preconiza a harmonização das políticas institucionais e permite que a universidade, ou qualquer modelo que atue no segmento da educação superior, possa se alinhar com o que prevê o tratado. Ao promover uma reflexão em função da construção da identidade institucional e do fortalecimento das lideranças na gestão da educação superior, o autor destaca uma tendência dinâmica para o segmento, a qual pode estar alinhada com o paradigma interpretativista de Morgan (1980), já que busca uma mudança de concepção por meio de uma leitura de mundo especifica da comunidade acadêmica.

Majora e Savin-Badenb (2010), ao analisarem o contexto do ensino e da aprendizagem, também destacam que a mudança de concepção também vem afetando a estrutura da educação superior inglesa a partir da introdução dos métodos qualitativos no processo de ensino, por meio do incentivo da pesquisa aplicada. Isso permite que a aprendizagem se constitua de modo dinâmico e reflexivo, fazendo com que se abra mão dos velhos paradigmas que pregam a simples transmissão do conhecimento descontextualizado, fortalecendo a tendência interpretativa também está presente em um contexto no qual a educação superior é um instrumento de desenvolvimento social reconhecido pela sociedade.

Os trabalhos de Walser (2009) e Tarí (2011) também congregam dessa ideia e destacam que a visão de mundo do processo de autoavaliação está vinculada ao desenvolvimento interno da instituição universitária, permeando todos os aspectos do projeto institucional e fortalecendo a dinâmica de participação social na construção do processo de aprendizagem. As visões dos autores se complementam, sendo que Walser (2009) destaca que a autoavaliação formativa é um instrumento substancial para incluir o estudante no contexto da formação por competências, orientando a instituição para o entendimento dos principais conhecimentos, habilidades e atitudes que devem constituir a base das atividades institucionais. Já o trabalho de Tarí (2011), que tinha o objetivo de analisar as diferenças entre as abordagens da autoavaliação, destaca que o sucesso do processo está baseado nas condições processuais e nos fatores condicionais, fortalecendo a tendência do processo para uma visão de mundo interpretativista.

No contexto da educação superior em Portugal, os trabalhos de Pacheco (2014), Morgado (2014) e Machado (2014) fortalecem essa visão, destacando que algumas iniciativas buscam equilibrar as visões pragmáticas e qualitativas, numa perspectiva funcionalista e 
interpretativista. Isso se dá em função do momento pelo qual passa a educação em Portugal, buscando uma nova epistemologia que possa permitir um desenvolvimento sustentável do segmento a partir de uma influência dinâmica da Europa e fortalece a visão de que a educação superior passa por uma alteração substancial em seu paradigma, especialmente em função da importância da autoavaliação como mecanismo norteador. Desse modo, a autoavaliação se torna um mecanismo para o reconhecimento da aplicação e eficácia das políticas públicas, mas também surge como uma forma de fortalecer a participação dos agentes institucionais na construção de uma visão de mundo customizada para cada modelo, fortalecendo a dinâmica interpretativa do processo de gestão.

A partir da analise dos trabalhos, portanto, é possível inferir que a educação superior no contexto europeu, o qual congrega grande parte das instituições de destaque no contexto desse modelo de educação, utiliza a autoavaliação como base para a construção de uma visão de mundo baseada na participação social e na construção qualitativa de sua realidade. Com base nos pressupostos elencados por Morgan (1980), percebe-se que o paradigma interpretativista é a visão de mundo dominante e hegemônica nesse contexto, constituindo, ao longo de todo o percurso europeu, a mudança paradigmática.

\subsection{Tendências no Brasil}

A autoavaliação, desde o inicio dos anos de 1980, é um mecanismo substancial na definição das políticas institucionais, que podem subsidiar a ação governamental, na educação superior brasileira. Com o Programa de Avaliação Institucional das Universidades Brasileiras (PAIUB), discutido à exaustão por Polidiri, Fonseca e Larrosa (2007), o processo foi sendo constituído na perspectiva da profissionalização, buscando incluir conceitos de gestão no contexto da universidade e fortalecer a participação da comunidade acadêmica na discussão sobre a relevância da educação superior.

A partir de 1995, com o arcabouço legal constituído para isso, a avaliação passa a ser um instrumento substancial para o fortalecimento das ações institucionais e também é utilizada como parâmetro para a orientação de oferta no contexto da educação superior. Isso se deu em função de uma lógica econômica e que surge como uma dinâmica de mercantilização da educação superior.

De 1996 até 2003, de acordo com Monteiro (2012), a expansão da educação superior ocorre por meio de mecanismos jamais vistos, e se dá, sobretudo, pela atividade das instituições privadas. Essas instituições se instalaram em cidades do interior e 
geograficamente distantes das capitais e grandes centros, que abrigavam as universidades federais e estaduais. O cenário que se construiu fez com que a autoavaliação ganhe conotações diferentes em contextos que possuíam, à época, objetivos dissonantes quanto ao processo de construção de uma nova epistemologia para a educação superior brasileira e que ainda podem ser identificados nos trabalhos publicados sobre o tema.

No âmbito da política governamental e das propostas de desenvolvimento do segmento da educação superior e autoavaliação, em um primeiro momento, surge como um instrumento de regulação a partir de práticas que se voltavam apenas para os conceitos de eficácia, sob uma perspectiva de avaliação de produto e não do processo. Foi um momento no qual o "Provão", nome dado ao Exame Nacional de Cursos (ENC), estava voltada para uma avaliação quantitativista e aplicada ao desempenho do estudante, onde o resultado determinaria o rumo da instituição. No caso de um resultado abaixo do conceito instituído como padrão político, a instituição, independente do modelo, passava a ter o seu ato regulatório discutido e podendo, até mesmo, sofrer sanções em seu credenciamento.

Em 2004, com a criação do SINAES, Thives Junior (2007) destaca que a concepção da autoavaliação passa para a vertente emancipatória, já que o SINAES institui princípios que deveriam se constituir como base para o fortalecimento do processo de gestão da instituição. Além da gestão, a autoavaliação apregoada pelo SINAES também deveria servir de referencial básico para os processos regulatórios, desde que fosse observada a característica dominante do modelo de gestão da instituição e, principalmente, sua relevância social.

Polodiri, Araujo e Barreyro (2006) também discutem essa concepção e fortalecem o argumento de que a autoavaliação passaria a ser um mecanismo que promoveria a emancipação da educação superior em um contexto institucional. Isso demandaria uma participação social incrementada e o fortalecimento da relevância social da instituição, entendida como sendo o principal mecanismo que constitui a relação com a sociedade. Essa visão, contudo, é alterada pela complexidade que se criou ao longo dos anos, já que a capilaridade da educação superior, o envolvimento do segmento privado e a lógica mercantilista fez com que o estado, por meio de políticas governamentais, pudesse inferir no processo regulatório das instituições.

Por esses aspectos, além da voracidade da lógica mercantil e da livre concorrência aplicada a um segmento historicamente reconhecido como um bem social, surge um instrumento que buscou integrar os procedimentos de avaliação com uma visão regulatória, pragmática e funcionalista, aplicada ao controle da expansão de instituições e de curso. 
Esse retrato pode ser percebido no contexto atual, especialmente no trabalho de Barreyro e Rothen (2014), o qual destaca a política do governo "Lula" que buscou a expansão das universidades federais e o controle de qualidade das atividades do segmento privado. $\mathrm{O}$ trabalho permite inferir que a regulação foi um mecanismo substancial para o desenvolvimento de uma política de qualidade para o segmento privado, tendo a avaliação, e seus mecanismos adjacentes, como auxiliares nesse processo.

Outra tendência que se institui para o processo de autoavaliação pode ser percebida no contexto das universidades e instituições do segmento público, já que em função da autonomia prevista em lei, e que é usufruída pelas universidades federais, fez com que a autoavaliação ganhasse um contorno de instrumento vinculado ao processo de reflexão sobre o fomento de sua identidade, logo sob uma visão interpretativista.

Já para as instituições e universidades do segmento privado, a tendência segue o que é discutido nos trabalhos de Sguissardi (2008), já que o padrão mercantilista proposto pelas ações advindas das possibilidades constitucionais preconizou a privatização da educação superior brasileira. Neste caso, a autoavaliação torna-se um mecanismo aplicado, sobretudo, para a verificação prescritiva de aspectos que envolvem a regulação, minimizando a reflexão sobre a relevância social da instituição.

Desse modo, ao analisar as tendências predominantes no contexto da autoavaliação, percebe-se, sob uma analogia aos paradigmas preconizados por Morgan (1980), que no Brasil a tendência hegemônica que se constitui é vinculada a regulação e ao funcionalismo, construindo um cenário incoerente com o histórico dos trabalhos publicados sobre o tema no período do recorte metodológico escolhido pela pesquisa.

\section{CONSIDERAÇÕES FINAIS}

A sociedade contemporânea vem apresentando novos padrões dominantes que se aplicam à gestão organizacional e desencadeiam processos de aprendizagem e de construção de conhecimento, com a intenção de construir uma identidade compreensível àqueles que fazem parte de uma determinada comunidade organizacional. O trabalho de Steil e Pacheco (2009), além de destacar esse aspecto, salienta que é fundamental que a organização busque esse processo por meio de procedimentos que envolvam toda a sua comunidade, já que as pessoas são as principais responsáveis pelo conhecimento crítico da organização. Isso faz com que os padrões dominantes, os paradigmas e as metáforas que envolvem a gestão dessas 
organizações passem por uma ruptura abrupta, fortalecendo, entre outros aspectos, a necessidade da reconstrução de identidade dessas organizações.

Em nível mundial, a educação superior vem passando por transformações que surgem pela dinâmica regulatória que se impõem, sobretudo em países emergentes, que promovem uma mudança de percepção sobre a contribuição dessas instituições. Invariavelmente, quando isso ocorre, instituem-se novas formas de perceber toda a estrutura que se constitui para a produção de conhecimento. A educação superior, e nesse contexto inclui-se a universidade, se apropria de mecanismos que relativizam essa busca e auxiliam na construção de seu arcabouço epistemológico, criando uma estrutura que possa ser compreendida pela sociedade de modo a minimizar as crises que são destacadas por Groppo (2011).

Essa busca se utiliza da autoavaliação como mecanismo balizador das competências desenvolvidas pela instituição, tanto as alinhadas ao ensino quanto aquelas que se voltam à gestão, e estruturam a identidade dessa organização social de modo alinhado ao contexto. Como foi possível identificar na revisão realizada nesse artigo, tanto em nível mundial como no Brasil, o processo de avaliação interna se constituiu em mecanismo substancial para o desenvolvimento de um novo paradigma dominante na educação superior. A mudança de um padrão ou paradigma dominante quebra os princípios hegemônicos vigentes e constitui uma nova dinâmica desse modelo a partir de uma lógica complexa e que envolve a realidade de cada envolvido nesse contexto social.

Sob essa premissa, portanto, é possível inferir que a autoavaliação se tornou um mecanismo utilizado para que se constitua uma reflexão sobre os padrões dominantes que envolvem a educação superior, fortalecendo um processo participativo de desconstrução e reordenação da identidade desse tipo de instituição. Em nível mundial, especialmente pelos trabalhos internacionais e publicados no contexto europeu, percebe-se que essa ferramenta é muito mais do que um processo mecânico de aplicação de metodologias e se constitui como um sistema de desenvolvimento sócio-técnico-estrutural, o qual fortalece o processo de construção de um novo padrão dominante.

A autoavaliação é também uma forma de alteração da lógica que determina o modelo institucional vigente na educação superior, permitindo uma transposição de modelos que valoriza o padrão interpretativista, destacado por Morgan (1980) como sendo altamente produtivo no âmbito do processo gerencial. Essa visão se consolida em nível internacional, já é possível identificar essa tendência nos trabalhos publicados, e na mesma proporção em nível nacional, especialmente pela implantação dos princípios que são expostos no SINAES e que 
orientam o processo de autoavaliação e, consequentemente, de avaliação institucional da educação superior. Portanto, pode-se inferir que a autoavaliação, em função das tendências que se apresentam, se alinha a um paradigma preponderantemente e predominantemente interpretaitivo, apoiando a construção reflexiva da identidade institucional.

Sob a orientação dessa lógica, a autoavaliação também é um instrumento que determina importantes construções no contexto gerencial das instituições, especialmente no modelo do SINAES, já que permite uma análise sistemática da estrutura de gestão e auxilia na construção de métodos gerenciais e metáforas que permitem a consecução dos objetivos apresentados no projeto institucional. Ao se utilizar desse processo como mecanismo auxiliar à gestão, automaticamente há uma transposição de lógica dominante e uma significativa alteração de paradigma no âmbito gerencial da educação superior. Porém, ao comparar os trabalhos internacionais, sobretudo os europeus com os brasileiros, percebe-se uma dicotomia existente e uma forte influência político-legal no Brasil, a qual se determina um contexto funcionalista e regulatório.

Essa dicotomia se caracteriza pela lógica interpretativista, vinculada ao contexto internacional, e que apregoa o desenvolvimento técnico e estrutural da instituição da educação superior na Europa e pela lógica funcionalista, regulatória e somativa, que se encontra no contexto brasileiro.

No âmbito internacional, tendo como base trabalhos europeus, mas que sugerem uma indução desses princípios para o contexto asiático e norte-americano, há uma demanda que determina a participação da comunidade acadêmica na construção de visão de mundo que permite uma influência direta na gestão institucional. Essa visão determina que cada modelo de instituição se constitua sob uma interdependência do contexto, incentivando substancialmente a participação social, por meio da autoavaliação, no desenvolvimento de uma identidade para a instituição e, consequentemente, para a educação superior.

No Brasil, apesar de uma tentativa de se desenvolver um modelo que promovesse e permitisse a autonomia e a liberdade no contexto gerencial das instituições e que se deu com o PAIUB e posteriormente com a introdução do SINAES, a lógica mercantil se estabeleceu no contexto nacional e ensejou o fortalecimento de um controle do estado sobre a educação superior. Em 2008, após diversas tentativas de fortalecer princípios alinhados ao paradigma interpretativista, surgem as premissas que regulam a atividade gerencial e de expansão do segmento da educação superior na contemporaneidade, fortalecendo uma lógica funcionalista, somativa e, por consequência, regulatória. 
O segmento público da educação superior, pouco afetado por essa lógica em função da autonomia que possui, foi base para a construção desse modelo de regulação, já que possui um modelo ideologicamente validado para política governamental do Brasil para a educação superior. As bases que se constituíram, reduziram a autoavaliação a um mecanismo de controle, determinando que a qualidade pudesse se constituir sob uma lógica inversamente proporcional a lógica do mercado, a qual determinou e orientou a expansão do segmento privado. Dessa forma, no contexto brasileiro, a lógica predominante é a funcionalista, determinando a regulação e o controle somativo das atividades institucionais, voltando-se para a punição em detrimento da participação.

Esse modelo é considerado destoado por Monteiro (2012), pois demonstra diversas incoerências com a realidade brasileira, sobretudo a do interior do país, já que determina condições que podem ser consideradas, até mesmo, inconstitucionais. Porém, vigente até o momento, a tendência é a continuidade desse pressuposto, fortalecendo a lógica dominante e hegemônica do funcionalismo.

\section{Agradecimentos}

Agradecemos à colaboração e contribuições do pesquisador Thiago Henrique Almino Francisco, doutorando pelo programa de Pós-Graduação em Engenharia e Gestão do Conhecimento (EGC) da Universidade Federal de Santa Catarina (UFSC).

\section{REFERÊNCIAS}

AUGUSTO, Rosana; BALZAN, Newton Cesar. A vez e a voz dos coordenadores das CPAs das IES de Campinas que integram o SINAES. Avaliação. Campinas; Sorocaba, SP, v. 12, n. 4, p. 597-622, dez. 2007.

BARREYRO, Gladys Beatriz. De exames, rankings e mídia. Avaliação. Campinas; Sorocaba, SP, v. 13, n. 3, p. 863-868, nov. 2008.

BARREYRO, Gladys Beatriz; ROTHEN, José Carlos. Percursos da avaliação da educação superior nos governos Lula. Educação e Pesquisa. São Paulo, v. 40, n. 1, p. 61-76, jan./mar. 2014.

BITTENCOURT, Hélio Radke; CASSARTELLI, Alam de Oliveira; RODRIGUES, Alziro César de Morais. Sobre o índice geral de cursos. Avaliação. Campinas; Sorocaba, SP, v. 14, n. 3, p. 667-682, nov. 2009.

BITTENCOURT, Hélio Radke; VIALI, Lori; CASSARTELLI, Alam de Oliveira; RODRIGUES, Alziro César de Morais.. Mudanças nos pesos do CPC e seu impacto nos 
resultados de avaliação em universidades federais e privadas. Avaliação. Campinas; Sorocaba, SP, v. 15, n. 3, p. 147-166, nov. 2010.

BRASIL. Portaria normativa No 23 de 29 de dezembro de 2010. Altera dispositivos da Portaria Normativa $\mathrm{n}^{\mathbf{0}} 40$, de 12 de dezembro de 2007, que Institui o e-MEC, sistema eletrônico de fluxo de trabalho e gerenciamento de informações relativas aos processos de regulação, avaliação e supervisão da educação superior no sistema federal de educação, e o Cadastro e-MEC de Instituições e Cursos Superiores e consolida disposições sobre indicadores de qualidade, banco de avaliadores (Basis) e o Exame Nacional de Desempenho de Estudantes (ENADE) e outras disposições. Acesso em: 12/04/2011. Disponível em: http://www.semesp.org.br/portal/pdfs/juridico2011/Portarias/Janeiro/PORTARIA\%20N\%202 3\%20-1-12-10.pdf. Casa Civil.

BRASIL. Portaria Normativa No $^{\circ}$, de 13 de dezembro de 2007. Institui o e-MEC, sistema eletrônico de fluxo de trabalho e gerenciamento de informações relativas aos processos de regulação da educação superior no sistema federal de educação. Acesso em 10/05/2011. Disponível em: http://www.consuni.ufrj.br/legislacao/portarianormativa40.pdf. Casa Civil. 2007.

DE SORDI, Mara Regina Lemes. Comissão própria de avaliação (CPA): similaridades e dessemelhanças no uso da estratégia na educação superior e em escolas do ensino fundamental. Avaliação. Campinas; Sorocaba, SP, v. 16, n. 3, p. 603-617, nov. 2011.

DIAS, Carmem. L.; HORIGUELA, Maria de Lourdes.; MARCHELLI, Paulo. S Políticas para a avaliação da qualidade do ensino superior no Brasil: um balanço crítico. Educação e Pesquisa, v. 32, n.3, p. 435-64. 2006.

ESTEVES, Paulo Cesar Leite . Fatores determinantes de mudanças na estrutura competitiva do sistema de ensino superior de Santa Catarina. Tese. 154f. (Tese de Doutorado). Programa de Pós-Graduação em Engenharia e Gestão do Conhecimento. Universidade Federal de Santa Catarina. 2007.

ETZKOWITZ, Henry. Anatomy of the entrepreneurial university. Studies of science/Etudes sur la science. 52: 486. 2013.

ETZKOWITZ, Henry; RANGA, Marina; BENNER, Mats; GUARANYS, Lucia; MACULAN, Anne Marie; KNELLER, Robert. Pathways to the entrepreneurial university: towards a global convergence. Science and Public Policy. November. 2008

FRANCISCO, Thiago Henrique Almino; MELO, Pedro Antônio de; NUNES, Rogério Silva; MICHELS, Expedito; AZEVEDO, Maria Ines Nava. Contribuições da avaliação in loco como fator de consolidação dos princípios estruturantes do SINAES. Avaliação, Campinas; Sorocaba, SP, v. 17, n. 3, p. 851-876, nov. 2012.

GROPPO, Luís Antonio. Da universidade autônoma ao ensino superior operacional: considerações sobre a crise da universidade e a crise do Estado nacional. Avaliação. Campinas; Sorocaba, SP. vol.16, n.1, pp. 37-55. 2011.

KUHN, Thomas S. A estrutura das revoluções científicas. $5^{\text {a }}$ ed. São Paulo. Editora Perspectiva. 1998. 
KURELIC, Zoran. How not to defende your tradition of higher education. Politička misao, Vol. 46, No. 5, 2009, pp. 9-20. 2009.

KUSHIMOTO, Takeshi. Outcomes assessment and its role in self-reviews of undergraduate education: in the context of Japan hoher education reforms since the 1990s. Springer

Science+Business. Media B.V. 2009.

MACHADO, Eusébio André. Entre omniavaliação e confiscação: contributos para uma avaliação dialógica e sustentável. Avaliação. Campinas; Sorocaba, SP, v. 19, n. 2, p. 333-343, jul. 2014.

MAJORA, Claire; SAVIN-BADENB, Maggi. Exploring the relevance of qualitative research synthesis to higher education research and practice. London Review of Education 0+9+-9 Vol. 8, No. 2, July. 2010

MARCHELI, Paulo Sérgio. O sistema de avaliação externa dos padrões de qualidade da educação superior no Brasil: considerações sobre os indicadores. Ensaio: aval. pol. públ. Educ., Rio de Janeiro, v. 15, n. 56, p. 351-372, jul./set. 2006.

MARQUES, Maria da Conceição da Costa. O novo sistema de avaliação e acreditação do ensino superior: impacto, repercussões e benefícios. Revista Universo Contábil, FURB, v. 6, n.1, p. 142-155, jan./mar. 2010.

MENDES, Karina Dal Sasso; SILVEIRA, Renata Cristina de Campos Pereira; GALVÃO, Cristina Maria. Revisão integrativa: método de pesquisa para a incorporação de evidências na saúde e na enfermagem. Texto Contexto Enfermagem, Florianópolis, Out-Dez; 17(4): 75864. 2008.

MO, Ching Mok; LUNG, Ching Leung; CHENG, Doris Pui Wah; CHEUNG, Rebecca Hu Ping; LEE, Mei. (2006). Self-assessment in higher education: experience in using a metacognitive approach in five case studies. Assessment \& Evaluation in Higher Education Vol. 31, No. 4, August 2006, pp. 415-433. 2006.

MONTEIRO, Carlos. $O$ desafio de colocar 10 milhões de estudantes no ensino superior. Estudos e projeções: panorama e propostas. Trabalho apresentado no IV Congresso Brasileiro da Educação Superior Particular. Salvador. 2011.

MORGADO, José Carlos. Avaliação e qualidade do desenvolvimento profissional docente: que relação. Avaliação. Campinas; Sorocaba, SP, v. 19, n. 2, p. 345-361, jul.2014.

MORGAN, Gareth. Paradigms, metaphors, and puzzle solving in organization theory. Administrative Science Quarterly. Vol. 25. No 4. 1980.

MORHY, Lauro (Org.). Universidade em questão. Brasília: Editora Universidade de Brasília. 2003.

NAIR, Praba; PRAKASH, Kamlesh (eds.) Knowledge Management: Facilitator's Guide. APO: Tokyo. 2009. 
NATHAN, Joshua D; WHATLEY, Art. Critical theory: a means for transforming organization development. Organization Development Journal. Volume 24. Number 2. Summer. 2006.

OLIVEIRA, Ana Paula de Matos; SOUZA, Valdinei Costa; SOUSA, José Vieira de; TAVARES, Érica Pâmela Goulart. Políticas de avaliação e regulação da educação superior brasileira: Percepções de coordenadores de licenciaturas no distrito federal. Avaliação.

Campinas; Sorocaba, SP, v. 18, n. 3, p. 629-655, nov. 2013.

ONG, Victor Yu Sing. Complexities of multiple paradigms in higher education leadership. Journal of Glbal Management. Vol.4 N.1. July. 2012.

PACHECO, José Augusto.Políticas de avaliação e qualidade da educação. Uma análise crítica no contexto da avaliação externa de escolas, em Portugal. Avaliação. Campinas; Sorocaba, SP, v. 19, n. 2, p. 363-371, jul. 2012.

PATTERSON, Glenys. Harmony through Diversity: Exploring an ecosystem paradigm for higher education. Journal of Higher Education Policy and Management. Vol. 26, No. 1, March. 2004.

PEIXOTO, Maria do Carmo de Lacerda. Avaliação institucional externa no SINAES:

Considerações sobre a prática recente. Avaliação. Campinas; Sorocaba, SP, v. 16, n. 1, p. 1136, mar. 2011.

PINTO, Rafael Ângelo Bunhi. Universidade comunitária e avaliação institucional: o caso das universidades comunitárias gaúchas. Avaliação. Campinas; Sorocaba, SP, v. 14, n. 1, p. 185215, mar. 2009.

POLIDORI, Maris M..; ARAUJO, Claisy M. Marinho; BARREYRO, Gladys. SINAES: perspectivas e desafios na avaliação da educação superior brasileira. Ensaio: aval. pol. públ. Educ., Rio de Janeiro, v.14, n.53, p. 425-436, out./dez. 2006.

POLIDORI, Marlis Morosini. Políticas de avaliação da educação superior brasileira: Provão, SINAES, IDD, CPC, IGC e...outros índices. Avaliação. Campinas; Sorocaba, SP, v. 14, n. 2, p. 267-290, jul. 2009.

POLIDORI, Marlis Morosini; FONSECA, Denise Grosso da; LARROSA, Sara Fernanda Tarter. Avaliação institucional participativa. Avaliação. Campinas; Sorocaba, SP. v. 12 n. 2 jun. 2007.

RIBEIRO, Elisa Antonia. As atuais políticas públicas de avaliação para a educação superior e os impactos na configuração do trabalho docente. Avaliação. Campinas; Sorocaba, SP, v. 17, n. 2, p. 299-316, jul. 2012.

SCHEJBAL, David. In search of a New Paradigm for Higher Education. Springer Science+Business Media, LLC. 2012.

SGUISSRDI, Valdemar. Regulação estatal versus cultura de avaliação institucional? Avaliação. Campinas; Sorocaba, SP, v. 13, n. 3, p. 857-862, nov. 2008. 
SILVA, Assis Leão; ALFREDO, Macedo Gomes. (2011). Avaliação institucional no contexto do SINAES: A CPA em questão. Avaliação. Campinas; Sorocaba, SP, v. 16, n. 3, p. 573 601, nov.

SOBRINHO, José Dias. Avaliação e transformações da educação superior brasileira (19952009): do Provão ao SINAES. Avaliação. Campinas; Sorocaba, SP, v. 15, n. 1, p. 195-224, mar. 2010.

SOUZA, Marcela Tavares; SILVA, Michelly Dias; CARVALHO, Rachel. Revisão Integrativa: o que é e como fazer. Einstein.; 8(1 Pt 1):102-6. 2010.

STEIL, Andrea Valéria; PACHECO, Roberto. Aprendizagem organizacional e criação do conhecimento em um instituto privado de ciência e tecnologia. Estratégia e Negócios, Florianópolis, v. 1, n. 2, jul./dez. 2008.

TARÍ, Juan José. Similarities and diferences between self-assessment approaches in public services in higher education institutions. The Service Industries Journal Vol. 31, No. 7, May 2011, 1125-1142. 2011.

THIVES JÚNIOR, Juarez Jonas. Competências para dimensões do sistema nacional de avaliação da educação superior- SINAES. 215 fls. Tese de Doutorado. Programa de PósGraduação em Engenharia de Produção da Universidade Federal de Santa Catarina.

Florianópolis. 2007.

VIEIRA, Regina Lúcia Bastos; FREITAS, Kátia Siqueira de. O SINAES na universidade pública estadual: análise do processo de construção da avaliação interna na Universidade do Estado da Bahia (UNEB). Ensaio: avalição e políticas públicas em educação. Rio de Janeiro, v. 18, n. 68, p. 443-464, jul./set. 2010.

WALSER, Tamara M. An action research study of student self-assesment in higher education. Innov High Educ.2009.

WEBER, Silke. Avaliações e regulação da educação superior: Conquistas e impasses. Educação e Sociedade. Campinas, v. 31, n. 113, p. 1247-1269, out.-dez. 2010.

WELSH, Helga A. Higher Education in Germany. Fragmented change amid paradigm shift. German Politics and Society, Issue. 95 Vol. 28, No. 2 Summer. 2010.

ZANDAVALLI, Carla Bussato. Avaliação da educação superior no Brasil: Os antecedentes históricos do SINAES. Avaliação. Campinas; Sorocaba, SP, v. 14, n. 2, p. 267-290, jul. 2009. 